\title{
Lifestyle factors during acute Epstein-Barr virus infection in adolescents predicts' physical activity six months later.
}

Maria Pedersen, MD ${ }^{a}$ Tarjei Tørre Asprusten, MD ${ }^{b}$ Kristin Godang, BSc ${ }^{c}$ Truls Michael

Leegaard, $\mathrm{PhD}{ }^{\mathrm{b}, \mathrm{d}}$ Liv Toril Osnes, $\mathrm{PhD}^{\mathrm{e}}$ Eva Skovlund, $\mathrm{PhD}^{\mathrm{f}}$ Trygve Tjade, $\mathrm{MD}^{\mathrm{g}}$ Merete

Glenne Øie, PhD ${ }^{\mathrm{h}, \mathrm{i}}$ Vegard Bruun Bratholm Wyller, $\mathrm{PhD}^{\mathrm{b}, \mathrm{j}}$

a'Dept. of Pediatrics, Vestre Viken Hospital Trust, Drammen , Norway

bInstitute of Clinical Medicine, University of Oslo, Oslo, Norway

${ }^{\mathrm{c} S e c t i o n}$ of Specialized Endocrinology, Dept. of Endocrinology, Oslo University Hospital, Oslo, Norway

${ }^{\mathrm{d}}$ Dept. of Microbiology and Infectional Control, Akershus University Hospital, Lørenskog,

Norway

${ }^{\mathrm{e}}$ Dept. of Immunology, Oslo University Hospital, Oslo, Norway

${ }^{\mathrm{f}}$ Norwegian Institute of Public Health, Oslo, Norway

${ }^{\mathrm{g}}$ Fürst Medical Laboratory, Lørenskog, Norway

${ }^{\text {h }}$ Dept. of Psychology, University of Oslo, Oslo, Norway

${ }^{\mathrm{i}}$ Research Division, Innlandet Hospital Trust, Lillehammer, Norway

${ }^{j}$ Dept. of Pediatrics, Akershus University Hospital, Lørenskog, Norway

Correspondence

Maria Pedersen, Dept. of Pediatrics, Vestre Viken Hospital Trust, N-3004 Drammen, Norway. Email: marpeders@gmail.com. Cell phone: +4795 771170.

Short running title

Physical activity following Epstein-Barr virus infection 


\begin{abstract}
Aim: Acute Epstein-Barr virus (EBV) infection is a trigger of prolonged fatigue. This study investigated baseline predictors of physical activity six months after an acute EBV infection.
\end{abstract}

Methods: A total of 200 adolescents (12-20 years old) with acute EBV infection were assessed for 149 possible baseline predictors and followed prospectively. We performed linear regression analysis to assess possible associations between baseline predictors and steps per day at six months.

Results: In the final multiple linear regression model, physical activity six months after acute EBV infection was significantly and independently predicted by baseline physical activity (steps per day), substance use (alcohol and illicit drugs), and human growth hormone (adjusted $\left.\mathrm{R}^{2}=0.20\right)$.

Conclusion: Physical activity six months after acute EBV infection is to a larger extent predicted by baseline variables related to lifestyle factors than to baseline variables reflecting infectious and immune processes. Physical activity during acute EBV infection seems to facilitate physical activity six months later.

\title{
Key Notes
}

- Lifestyle factors are the main predictors for physical activity six months following acute Epstei-Barr virus (EBV) infection.

- The intensity or quality of infectious- and immune processes does not seem to predict. 
- Physical activity during acute EBV-infection seems to facilitate physical activity six months later.

Keywords: Physical activity, Epstein-Barr virus infection, adolescents, chronic fatigue 


\section{Background}

Epstein-Barr virus (EBV) is a common human pathogen causing a replicative infection in the oropharynx as well as a life-long latent infection of B cells (1). In children, a primary EBV infection normally elicits few, if any, symptoms. In adolescence, however, up to $75 \%$ of infected individuals develops infectious mononucleosis (IM) characterized by fever, pharyngitis, swollen lymph nodes and malaise (2-4). In the adult population, more than $90 \%$ have undergone an EBV infection.

IM is often complicated by prolonged fatigue, and as many as $12-13 \%$ of EBV-infected individuals fulfill case definition of chronic fatigue syndrome (CFS) six months after the acute infection $(5,6)$. Predictors of chronic fatigue development include female sex, previous negative life events, symptom intensity and C-reactive protein (CRP) level during the initial stages of EBV infection (7-11). However, in a recent study, virus load and other infectious markers had no predictive power(11).

Earlier studies suggest that CFS patients have lower activity levels compared to healthy controls (12-14). Graded exercise is an integrated part of some therapy protocols for CFS(15), and physical activity may modulate illness experiences $(16,17)$ and increase general well-being $(17$, 18). Furthermore, physical activity impacts markedly on immune processes and might influence underlying disease processes involving the immune system $(19,20)$.Accordingly, physical activity monitoring has been used as primary endpoint in CFS clinical trials (14).

Still, the relationship between physical activity and chronic fatigue remains to be fully characterized. In particular, predictors of reduced activity level after acute EBV infection has - to the best of our knowledge - never been investigated. Identification of such predictors might inform prophylactic measures as well as rehabilitation programs, and also yield insight into the underlying mechanisms of disability development in post-infectious chronic fatigue and CFS. 
Thus, the aim of the present study was to investigate predictors of physical activity six months after acute EBV infection in adolescents. We hypothesized that factors related to symptoms and function, and not infection and immune response, will be the main predictors for physical activity, similar to previously identified predictors of fatigue in the same cohort.

\section{Materials and methods}

\section{Study design}

This study is a part of the CEBA-project (Chronic Fatigue following acute Epstein-Barr virus Infection in Adolescents; ClinicalTrial ID: NCT02335437), embracing a prospective, crosssectional and randomized controlled design with a total follow-up time of 21 months. A detailed description has been provided elsewhere(11). Here, only prospective results from the first six months are reported. The project has been approved by the Norwegian National Committee for Ethics in Medical research. All participants provided written informed consent before inclusion.

\section{Participants with EBV infection}

Inclusion of participants lasted from March 2015 until November 2016. During this period, EBV infected individuals fulfilling the following criteria were assessed for eligibility(11): a) A serological pattern indicating acute EBV infection (Table 1); b) Age between 12 and 20 years; and c) Living in one of the Norwegian counties Oslo, Akershus or Buskerud. Exclusion criteria were a) More than 6 weeks since debut of symptoms suggesting acute EBV infection; b) Any chronic disease that needed regular use of medication; and c) Pregnancy. 
Participants were summoned to a one-day investigational program at the CEBA study center, Akershus University Hospital, Norway. Encounters were scheduled as soon as possible after debut of symptoms (baseline), with a follow-up visit 6 months later. All participants met at 8 a.m. after fasting overnight. They brought morning spot urine in a sterile container, and were instructed to apply a local anesthetic ointment (EMLA®, AstraZeneca) on both antecubital areas one hour before arriving.

The investigational program was carried out in a fixed sequence for all participants by two researchers only (MP and TTA), and included a clinical examination, ultrasound of the spleen, blood and throat swab sampling, autonomic cardiovascular control assessment, pressure pain threshold assessment, cognitive testing and questionnaire charting(11). Blood samples were obtained in a fixed sequence from antecubital venous puncture and assayed for neuroendocrinological, immunological, microbiological, and routine clinical markers. Autonomic testing encompassed continuous, non-invasive recordings of blood pressure, heart rate and stroke volume during 1) supine rest, 2) supine rest with controlled breathing, and 3) upright standing featuring the Task Force Monitor (Model 3040i, CNSystems Medizintechnik, Graz, Austria). Pressure pain threshold was assessed by gradually applying increasing pressure to six predefined areas, using the Commander ${ }^{\mathrm{TM}}$ Algometer (JTECH Medical, Midvale, USA). Cognitive test included assessment of working memory, processing speed, cognitive inhibition and flexibility, learning, and memory. The questionnaire included validated inventories of fatigue and CFS, pain, sleep problems, anxiety and depression, worrying, emotional awareness, illness perceptions, perfectionism, life events, quality of life, and functional disabilities. In addition, we included questions regarding clinical symptoms of EBV infection, symptoms pertaining to different case definition of CFS $(21,22)$, and demographic and lifestyle background variables. 


\section{Activity monitoring}

Activity monitoring was initiated immediately after the in-hospital investigational program. All participants wore the activPAL ${ }^{\mathrm{TM}}$ accelerometer device (PAL Technologies, Glasgow, Scotland) for seven consecutive days. The activPAL ${ }^{\mathrm{TM}}$ was attached on the anterior midline on the participants thigh with costum made, waterproof adhesive tape. The participants were instructed to wear the activPAL ${ }^{\mathrm{TM}}$ at all times, and only take it off when the recording period was finished. The activPAL ${ }^{\mathrm{TM}}$ provides reliable data on both steps and position $(23,24)$, and is validated for adolescents (25).

Data from the recording units was transferred to a computer running producer developed software. For each participant, all recording epochs were carefully and independently reviewed by two of the authors (MP and TTA). Alternating periods of active and sedentary behavior were required each day; if one recording day was considered to contain erroneous or incomplete data, that entire day was removed from further calculation (Table 2). Doubtful cases were discussed until consensus was reached.

\section{Statistical analysis}

All statistical analyses were performed with SPSS statistical software (IBM SPSS Statistic 22 Inc., Chicago, IL, USA). Average steps per day at six months follow-up was predefined as the dependent variable (26). It was estimated that a total of $200 \mathrm{EBV}$ infected individuals would give a power of at least $80 \%$ to detect a predictor variable that explains $5 \%$ of the variance in steps per day at six months. Correspondingly, when assessing associations with a binary predictor at a $5 \%$ significance level, a total of 200 patients would give a power of $80 \%$ to detect a mean difference of 0.4 SD between the two categories. Thus, the study had sufficient power to detect small to medium effect sizes. 
The primary analyses featured simple linear regression between steps per day and a total of 149 possible baseline predictors (11). The first screening was performed without imputation and assumptions were checked by visual inspection of residual plots. Thereafter, variables with pvalue below 0.1 in the sceening analyses and thus candidates for inclusion in the multiple linear model, were subjected to multiple imputation to replace missing values, creating a total of five complete datasets. All six datasets (five imputed in addition to the original dataset) were included in multiple linear regression modelling assessing each variable's p-value and the effect on the dependent variable's variance (adjusted $\mathrm{R}^{2}$ ). In the final models, a p-value $<0.05$ was considered statistically significant. To check the stability of the model, all candidate variables were reentered one-by-one in the final model. A wide as well as a strict model were constructed: The wide model consists of all variables that ended up in the final model for one of the six datasets. The strict model was constructed on pooled data from the five imputed datasets. A more detailed explanation of a similar model construction is reported elsewhere (11).

+ sensitivitetsanalyse med bare complete cases? (kun final model)

\section{Results}

A total of 895 adolescents with a serological pattern suggesting acute EBV infection were assessed for eligibility, and a total of 200 were included, of which 195 (97.5\%) attended the follow-up visit at six months (Table 3). Serological analyses confirmed acute EBV infections in all included participants.

In simple linear regression analyses, baseline variables of clinical symptoms and functional abilities were most strongly associated with physical activity at six months (Table S1). In addition, baseline emotions, alcohol and narcotics consumption and supine heart rate had some 
predictive power, whereas few associations were found to markers of infection, immunity and neuroendocrinology.

In the final multiple linear regression model, baseline steps/day and narcotics consumption were positively and independently associated with steps/day at 6 months, whereas baseline alcohol consumption and serum growth hormone levels were negatively associated (Table 4). Applying a less strict procedure for variable selection, baseline sleepiness, emotional awareness, serum IgG level and supine heart rate added some explanatory power to the model (Table S2). Analyses stratified by sex revealed a higher explanatory power of the models for the females compared to the males. Baseline steps/day remained a statistically significant predictor among females only, whereas baseline alcohol and narcotics consumption were the only two significant predictors among males (Table S2). For narcotics, ten males and eight females had positive scores. For all the variables included in both the wider and the final model, there were none statistically significant gender interaction terms (in both unadjusted and adjusted models calculation not shown in any of the tables).

\section{Discussion}

In this study, the main finding was that baseline steps per day, substance use (alcohol and illicit drugs) and plasma growth hormone were independent predictors of physical activity six months after acute EBV infection, whereas variables reflecting immune or infectious disease processes had no or limited predictive power.

Steps per day at baseline was the most important predicting factor; the participants who were more active during acute illness were more active six months later. This finding may reflect habits; i.e., participants tend to keep up with their usual activities regardless of infectious episodes. Alternatively, physical activity might positively influence the recovery processes after 
infectious mononucleosis, as suggested by some previous reports $(16,17,19,20,27)$. Low physical activity during acute infection does not seem to be a measure for illness severity as variables reflecting symptom load, infectious and immune responses did not influence the final model.

Adjusting for baseline measurements of the dependent variable may cause interpretation challenges in observational studies (28). In the final model the estimates for substance use (alcohol/illicit drugs) and growth hormone did not change when baseline steps per day was removed from the final model. They also stayed the same in a model where change in steps per day was set as dependent variable.

Self-reported alcohol and narcotics/illicit drug consumption were also independent predictors in the final multiple linear regression model (Table 4). The association between alcohol consumption and physical activity was negative, in line with research on adults showing that high consumers are habitually less active than non- and moderate drinkers (29). Surprisingly, for narcotics/illicit drugs, the association in the present study was positive: Adolescents that used narcotics/illicit drugs tended to have a higher level of physical activity than the non-users. This result contrasts previous findings on sport participation among adolescents (30). A possible explanation might be that some of the participants in the present study use doping to promote sports achievements, or illicit stimulants; unfortunately, our data set does not allow us to pursue this hypothesis in the present study. Research on illicit drug use in Norway show that cannabis is the most prevalent illicit drug among adolescents (31). Baseline plasma growth hormone level was negatively associated with physical activity six months later. Growth hormone increases with different types of stress, such as physical activity as well as psychological challenges (32). Previous studies have shown that sedentary individuals have a higher growth hormone response to physical activity compared to fit individuals (33). In the present study, we speculate that those 
being less active at six months are less fit at baseline, which in turn might be associated with a stronger growth hormone response to the psychological distress of undergoing an extensive investigational program (34).

Interestingly, the large number of variables related to baseline infectious of immune processes showed little or no association to physical activity six months later. Thus, reduced physical activity six months after acute EBV infection does not seem to be a direct consequence of the infection per se, nor the related immune response.

An earlier publication on the same cohort identified variables related to symptoms and functions, as the best predictors for fatigue six months after acute EBV infection (11). Interestingly, this study also shows a low predictive value of variables reflecting infectious and immune processes. Otherwise, the prediction model for physical activity was strikingly different to the predicting model for fatigue. In CFS clinical trials, steps per day has been used as a proxy for treatment monitoring $\mathrm{i}(14)$. The difference in prediction-models questions this practice.

\section{Strengths and limitations}

Strengths of the present study are the large sample size of adolescents with acute EBV infection, the low number of drop-outs and the wide assessment of each participant. Ideally, participants should also have been assessed prior to the acute EBV infection, but this was not practically feasible.

The number of variables measured and included in the analysis poses a challenge in the interpretation of the results. Basing variable selection on p-values tends to lead to overestimation of associations, and there is also a high risk of false positive findings. Our model should therefore be regarded as exploratory rather than confirmatory. 
Another limitation is the missing activity data. A total of 27 (13.5\%) participants had no valid activity measurements six months after the acute EBV infection. Our primary analysis is based on multiple imputation of missing values. The main weakness of this strategy is that data are assumed to be missing at random, which is an assumption that is difficult to verify. The sensitivity analysis using only actual measurements showed.... which is somewhat reassuring, even if a complete case analysis is expected to be biased.

\section{Conclusion}

Baseline physical activity (steps per day), substance use (alcohol and illicit drugs), and plasma growth hormone are independent predictors of physical activity 6 months after an acute EBV infection in adolescents, whereas markers of the infection and associated immune response have weak predictive power. The possible benefit of physical activity in the acute phase of EBV infection should be addressed in further studies.

\section{List of abbreviations}

CEBA - Chronic fatigue following acute EBV infection in adolescents

CFS - Chronic Faigue Syndrome

CRP - C-reactive protein

EBV - Epstein-Barr virus

IM - Infectious Mononucleosis

\section{Declarations}

\section{Conflict of Interest}

None of the authors have conflict of interest or financial relationships relevant to this article to disclose. 


\section{Founding}

This study was founded by the Health South-East Hospital Trust, Norway. 


\section{References}

1. Epstein MA, Achong BG, Barr YM. Virus Particles in Cultured Lymphoblasts from Burkitt's Lymphoma. Lancet 1964; 1 7335:702-3.

2. Balfour HH, Jr., Odumade OA, Schmeling DO, Mullan BD, Ed JA, Knight JA, et al. Behavioral, virologic, and immunologic factors associated with acquisition and severity of primary EpsteinBarr virus infection in university students. J Infect Dis 2013; 207 1:80-8.

3. Henle G, Henle W, Diehl V. Relation of Burkitt's tumor-associated herpes-ytpe virus to infectious mononucleosis. Proc Natl Acad Sci U S A 1968; 59 1:94-101.

4. Rea TD, Russo JE, Katon W, Ashley RL, Buchwald DS. Prospective study of the natural history of infectious mononucleosis caused by Epstein-Barr virus. J Am Board Fam Pract 2001; 14 4:234-42.

5. Katz BZ, Shiraishi Y, Mears CJ, Binns HJ, Taylor R. Chronic fatigue syndrome after infectious mononucleosis in adolescents. Pediatrics 2009; 124 1:189-93.

6. Hickie I, Davenport T, Wakefield D, Vollmer-Conna U, Cameron B, Vernon SD, et al. Post-infective and chronic fatigue syndromes precipitated by viral and non-viral pathogens: prospective cohort study. BMJ 2006; 333 7568:575.

7. Buchwald DS, Rea TD, Katon WJ, Russo JE, Ashley RL. Acute infectious mononucleosis: characteristics of patients who report failure to recover. Am J Med 2000; 109 7:531-7.

8. Candy B, Chalder T, Cleare AJ, Peakman A, Skowera A, Wessely S, et al. Predictors of fatigue following the onset of infectious mononucleosis. Psychol Med 2003; 33 5:847-55.

9. Petersen I, Thomas JM, Hamilton WT, White PD. Risk and predictors of fatigue after infectious mononucleosis in a large primary-care cohort. QJM 2006; 99 1:49-55.

10. Chretien JH, Esswein JG, Holland WG, McCauley CE. Predictors of the duration of infectious mononucleosis. South Med J 1977; 70 4:437-9.

11. Pedersen M, Asprusten TT, Godang K, Leegaard TM, Osnes LT, Skovlund E, et al. Predictors of chronic fatigue in adolescents six months after acute Epstein-Barr virus infection: a prospective cohort study. Brain Behav Immun 2018.

12. Evering RM, Tonis TM, Vollenbroek-Hutten MM. Deviations in daily physical activity patterns in patients with the chronic fatigue syndrome: a case control study. J Psychosom Res 2011; 71 3:129-35.

13. Meeus M, van Eupen I, van Baarle E, De Boeck V, Luyckx A, Kos D, et al. Symptom fluctuations and daily physical activity in patients with chronic fatigue syndrome: a case-control study. Arch Phys Med Rehabil 2011; 92 11:1820-6.

14. Sulheim D, Fagermoen E, Winger A, Andersen AM, Godang K, Muller F, et al. Disease mechanisms and clonidine treatment in adolescent chronic fatigue syndrome: a combined crosssectional and randomized clinical trial. JAMA pediatrics 2014; 168 4:351-60.

15. Excellence NIfHaC. Clinical guideline CG53. Chronic fatigue/myalgic enc3phalomyelitis (or enc3phalopaty): diagnosis and management. 2007

16. Brown JD, Siegel JM. Exercise as a buffer of life stress: a prospective study of adolescent health. Health Psychol 1988; 7 4:341-53.

17. Penedo FJ, Dahn JR. Exercise and well-being: a review of mental and physical health benefits associated with physical activity. Curr Opin Psychiatry 2005; 18 2:189-93.

18. Gauvin L, Spence JC. Physical activity and psychological well-being: knowledge base, current issues, and caveats. Nutr Rev 1996; 544 Pt 2:S53-65.

19. Dhabhar FS. Effects of stress on immune function: the good, the bad, and the beautiful. Immunol Res 2014; 58 2-3:193-210.

20. Pedersen BK, Hoffman-Goetz L. Exercise and the immune system: regulation, integration, and adaptation. Physiol Rev 2000; 80 3:1055-81. 
21. Fukuda K, Straus SE, Hickie I, Sharpe MC, Dobbins JG, Komaroff A. The chronic fatigue syndrome: a comprehensive approach to its definition and study. International Chronic Fatigue Syndrome Study Group. Ann Intern Med 1994; 121 12:953-9.

22. Carruthers BM, Jain AK, De Meirleir KL, Peterson DL, Klimas NG, Lerner AM, et al. Myalgic Encephalomyelitis/Chronic Fatigue Syndrome. J CFS 2003; 11 1:7-115.

23. Grant PM, Ryan CG, Tigbe WW, Granat MH. The validation of a novel activity monitor in the measurement of posture and motion during everyday activities. Br J Sports Med 2006; 40 12:992-7.

24. Ryan CG, Grant PM, Tigbe WW, Granat MH. The validity and reliability of a novel activity monitor as a measure of walking. Br J Sports Med 2006; 40 9:779-84.

25. Dowd KP, Harrington DM, Donnelly AE. Criterion and concurrent validity of the activPAL professional physical activity monitor in adolescent females. PloS one 2012; 7 10:e47633.

26. Wyller VB. Statistical analysis plan - CEBA. 2014

27. Dalrymple W. Infectious Mononucleosis. Postgrad Med 1964; 35(4):345-349.

28. Lord FM. A paradox in the interpretation of group comparisons. Psychol Bull 1967; 68 5:304-5.

29. Liangpunsakul S, Crabb DW, Qi R. Relationship among alcohol intake, body fat, and physical activity: a population-based study. Ann Epidemiol 2010; 20 9:670-5.

30. Kwan M, Bobko S, Faulkner G, Donnelly P, Cairney J. Sport participation and alcohol and illicit drug use in adolescents and young adults: a systematic review of longitudinal studies. Addict Behav 2014; 39 3:497-506.

31. The Drug Situation in Norway. 2014

32. Greenwood F, Landon J. Growth hormone secretion in response to stress in man. Nature 1966; 210 5035:540.

33. Bloom SR, Johnson RH, Park DM, Rennie MJ, Sulaiman WR. Differences in the metabolic and hormonal response to exercise between racing cyclists and untrained individuals. J Physiol 1976; 258 1:1-18.

34. Jacobs HS, Nabarro JD. Plasma 11-hydroxycorticosteroid and growth hormone levels in acute medical illnesses. Br Med J 1969; 2 5657:595-8. 


\section{Tables}

\begin{tabular}{ccccr}
\hline \multicolumn{2}{l}{ Table 1. Serological patterns proving acute EBV infection } & & \\
\hline & EBV-VCA IgM & EBV-VCA IgG & EBNA IgG & Heterophile antibodies $^{1}$ \\
\hline Pattern 1 & Positive $(\geqslant 40 \mathrm{U} / \mathrm{ml})$ & Negative $(<20 \mathrm{U} / \mathrm{ml})$ & Negative $(<20 \mathrm{U} / \mathrm{ml})$ & Positive \\
Pattern 2 & Positive $(\geqslant 40 \mathrm{U} / \mathrm{ml})$ & Positive $(\geqslant 20 \mathrm{U} / \mathrm{ml})$ & Negative $(<20 \mathrm{U} / \mathrm{ml})$ & -
\end{tabular}

${ }^{1}$ The test for heterophile antibodies was only executed when the specific tests alone were inconclusive

Table 2. Number of activPAL registrations with days of valid recordings

\begin{tabular}{ccc}
\hline Days of valid recordings & Baseline & EBV patients \\
7 & 161 & 6 months \\
6 & 8 & 143 \\
5 & 9 & 7 \\
4 & 3 & 5 \\
3 & 2 & 5 \\
2 & 2 & 5 \\
All missing & 15 & 27 \\
\hline
\end{tabular}

Table 3. Cohort characteristics

$\begin{array}{ccc}\begin{array}{c}\text { Patients at } \\ \text { baseline } \\ (\mathrm{n}=200)\end{array} & \begin{array}{c}\text { Patients at six } \\ \text { months }\end{array} & \begin{array}{c}\text { p-value (baseline vs } \\ \text { six months })^{1}\end{array} \\ (\mathrm{n}=195) & \end{array}$

\section{Background}

Sex - no. males $(\%)$

$71(35.5 \%)$

n.a.

n.a.

Age, years - mean (SD)

$16.9(1.6)$

$17.4(1.6)$

$<0.001$

BMI, $\mathrm{kg} / \mathrm{m}^{2}$ - mean (SD)

$21.3(2.6)$

$22.2(2.6)$

$<0.001$

Symptoms and functional impairment

Days since debut of symptoms, self reported - mean (SD)

$30.2(6.6)$

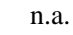

n.a.

Chalder Fatigue Questionnaire (CFQ), total score - mean (SD) ${ }^{3}$

$19.5(4.7)$

$15.2(5.1)$

$<0.001$

Infectious Symptoms, total score - mean (SD)

$2.7(0.9)$

$1.8(0.7)$

$<0.001$

Functional Disability Inventory, total score - mean (SD)

$16.6(11.8)$

$6.6(8.8)$

$<0.001$

Steps/day, number - mean (SD)

7515 (3080)

$9046(3438)$

$<0.001$

Clinical findings

Epstein-Barr Virus (EBV) load, copies in blood - no. (\%)

0.111

Negative $(<160)$

$49(24.9 \%)$

$82(43.6 \%)$

Low (1600 to 2000)

$115(58.4 \%)$

$61(32.4 \%)$ 
Moderate/high (>2000)

EBV Viral Capsid Antigen (VCA) IgM, titer - median (IQR)

EBV-VCA-IgG, titer - median (IQR)

EBV Nuclear Antigen (EBNA) IgG, titer - median (IQR)

Serum total IgG, g/L - mean (SD)

Blood Lymphocyte count, $10^{9}$ cells/L - median (IQR)

Serum Alanine Transaminase (ALT), IU/L - median (IQR)

$\begin{array}{ccc}33(16.8 \%) & 45(23.9 \%) & \\ 160(73) & 20(162) & <0.001 \\ 69(67) & 169(162) & <0.001 \\ 0(0) & 98(205) & <0.001 \\ 12.0(2.7) & 9.9(1.8) & <0.001 \\ 2.3(0.8) & 1.9(0.7) & <0.001 \\ 33(23) & 24(9) & <0.001\end{array}$

n.a.= not applicable. ${ }^{1}$ Based on t-test, Mann-Whitney test or chi-square test, as appropriate. ${ }^{2}$ Steps/day at 6 months is defined as the dependent variable for the prediction analyses, cf. Table 2 and 3.

Table 4. Baseline predictors of physical activity six months after acute EBV infection. Final multiple linear regression model

\begin{tabular}{|c|c|c|c|}
\hline & Linear regression coefficient $\mathrm{B}(\mathrm{CI})$ & p-value & $\Delta \operatorname{adj} . R^{23}$ \\
\hline Steps/day, number & $0.4(0.2$ to 0.6$)$ & $\mathrm{p}<0.001$ & 0.122 \\
\hline Usage of alcoholic beverages ${ }^{1}$ & $-1757(-2863$ to -651$)$ & 0.002 & 0.052 \\
\hline Usage of narcotics/illicit drugs ${ }^{1}$ & $2100(626$ to 3574$)$ & 0.005 & 0.031 \\
\hline Serum Growth Hormone, $\mu \mathrm{g} / \mathrm{L}$ & $-148(-266$ to -29.5$)$ & 0.015 & 0.025 \\
\hline Explained variance (adjusted $\mathrm{R}^{2}$ ) of model $\mathrm{l}^{5}$ & \multicolumn{3}{|c|}{0.34} \\
\hline
\end{tabular}





\begin{tabular}{|c|c|c|c|c|c|}
\hline \multirow[b]{2}{*}{ Background } & & \multicolumn{2}{|c|}{ original variables } & \multicolumn{2}{|c|}{ imputed variables } \\
\hline & & $\begin{array}{l}\text { Linear regression } \\
\text { coefficient B (CI) }\end{array}$ & $\begin{array}{c}\text { p- } \\
\text { value }\end{array}$ & $\begin{array}{l}\text { Linear regression } \\
\text { coefficient B }(\mathbf{C I})\end{array}$ & $\begin{array}{c}\text { p- } \\
\text { value }\end{array}$ \\
\hline Sex - no. males (\%) & $71(35.5 \%)$ & $-719(-1797$ to 359$)$ & 0.190 & & \\
\hline Age at inclusion, years - mean (SD) & $16.9(1.6)$ & $-212(-536$ to 113$)$ & 0.200 & & \\
\hline BMI, kg/m² - mean (SD) & $21.3(2.6)$ & 89.5 (-110 to 289$)$ & 0.376 & & \\
\hline Days since debut of symptoms, self reported - mean (SD) & $30.2(6.6)$ & $4.8(-78.4$ to 87.9$)$ & 0.910 & & \\
\hline \multicolumn{6}{|l|}{ Ethnicity - no. (\%) } \\
\hline Scandinavian & $184(92.5 \%)$ & & 0.208 & & \\
\hline Half Scandinavian & $10(5 \%)$ & $-75.5(-2288$ to 2137$)$ & & & \\
\hline Not Scandinavian & $5(2.5 \%)$ & $2769.0(-313$ to 5851$)$ & & & \\
\hline \multicolumn{6}{|l|}{ Lives with... - no. (\%) } \\
\hline ...both parents & $142(71.4 \%)$ & & 0.239 & & \\
\hline ...divorced parents, alternating & $17(8.5 \%)$ & $-1002(-2856$ to 852$)$ & & & \\
\hline ...one parent & $3517.5 \%)$ & $-666(-2028$ to 697$)$ & & & \\
\hline ...alone & $3(1.5 \%)$ & $3044(-915$ to 7003$)$ & & & \\
\hline ...other & $2(1 \%)$ & $-3772(-10575$ to 3031$)$ & & & \\
\hline \multicolumn{6}{|l|}{ Parents' highest education - no. (\%) } \\
\hline Primary school & $1(0.5 \%)$ & & 0.653 & & \\
\hline Secondary school & $47(23.9 \%)$ & $-3792(-10733$ to 3149$)$ & & & \\
\hline Lower university & $97(49.2 \%)$ & $-3931(-10827$ to 2965$)$ & & & \\
\hline Higher university & $52(26.4 \%)$ & $-3495(-10428$ to 3438$)$ & & & \\
\hline \multicolumn{6}{|l|}{ Siblings - no. (\%) } \\
\hline 0 & $29(14.5 \%)$ & & 0.580 & & \\
\hline 1 & $109(54.5 \%)$ & $-1002(-2582$ to 579$)$ & & & \\
\hline 2 & $47(47 \%)$ & $-417(-2207$ to 1373$)$ & & & \\
\hline$\geq 3$ & $15(7.5 \%)$ & $-557(-2817$ to 1702$)$ & & & \\
\hline \multicolumn{6}{|l|}{ Usage of alcoholic beverages - no. (\%) } \\
\hline Never & $69(36.7 \%)$ & $-1376(-2468$ to -2468$)$ & 0.014 & $-1348(-2440$ to -255$)$ & 0.016 \\
\hline Occationally & $119(63.3 \%)$ & & & & \\
\hline
\end{tabular}


Usage of tobacco products - no. (\%)

$$
\begin{aligned}
& \text { Never } \\
& \text { Occationally }
\end{aligned}
$$

Usage of narcotics/illicit drugs - no. (\%)

$$
\text { Never }
$$

Occationally

\section{Personality/life events}

Child and Adolescent Perfectionism Scale (CAPS), total score - mean (SD)

CAPS Subscore: Self oriented striving - mean (SD)

CAPS Subscore: Self oriented critical - mean (SD)

CAPS Subscore: Socially perscribed - mean (SD)

Life Event Checklist (LEC), total score of positive events last year - median (IQR)

LEC, total scor of all positive events - median (IQR)

LEC, total score of negative events last year- median (IQR)

LEC, total score of all negative events - median (IQR)

\section{Clinical symptoms}

Chalder Fatigue Questionnaire (CFQ), total score

Post-exertional Malaise, single item - mean (SD)

Infectious Symptoms, mean score - mean (SD)

Hypersensitivity Symptoms, mean score - mean (SD)

Brief Pain Inventory (BPI), total pain severity score - mean (SD)

BPI, average pain single item score - mean (SD)

Karolinska Sleep Questionnaire (KSQ), total score - mean (SD)

KSQ Subscore: Insomnia - mean (SD)

KSQ Subscore: Awakenings - mean (SD)

KSQ Subscore: Sleepy at daytime - mean (SD)

\section{Clinical findings}

Tympanic temperatur, ${ }^{\circ} \mathrm{C}$ - mean (SD)

$\begin{array}{ccc}107(56.9 \%) & -874(-1949 \text { to } 208) & 0.110 \\ 81(43.1 \%) & & \\ & & \\ 170(90.4 \%) & 1730(40.6 \text { to } 3419) & 0.045 \\ 18(9.6 \%) & & \\ & & \\ 36.6(10.15) & -18.4(-71.1 \text { to } 34.4) & 0.493 \\ 10.28(2.80) & 154(-35.9 \text { to } 343) & 0.111 \\ 9.73(3.65) & -60.0(-207 \text { to } 86.7) & 0.420 \\ 16.6(6.0) & -66.6(-157 \text { to } 24.0) & 0.149 \\ 7.0(7.0) & 14.9(-429 \text { to } 459) & 0.947 \\ 7.0(8.0) & 15.4(-408 \text { to } 439) & 0.943 \\ 5(8) & -219(-564 \text { to } 125) & 0.211 \\ 7(10) & -229(-562 \text { to } 104) & 0.176\end{array}$

19.5 (4.71)

$-117.3(-231$ to -3.1$)$
$-245(-646$ to 156$)$
$-949(-1557$ to -341$)$
$-520(-1077$ to 36.4$)$
$-186(-294$ to 77.8$)$
$-745(-1179$ to -311$)$
$68.9(25.6$ to 112$)$
$141(32.0$ to 250$)$
$157(4.2$ to 310$)$
$191(65.6$ to 316$)$

0.044

0.230

$1 \cdot 5(0 \cdot 6)$

$2.7(0.9)$

$1.7(1.0)$

10.9 (4.9)

$2.7(1.2)$

$52.5(12.4)$

$15.6(4.8)$

$10.2(3.6)$

$13.9(4.2)$

$36.3(0.5)$
1484 (-227 to 3195$)$

0.088
-95.1 (-209 to 18.2$)$

-825 (-1619 to -30.8$)$ $-406(-1072$ to 261$)$

$-156(-267$ to -43.7$)$ $-622(-1070$ to 175$)$

58.5 (12.5 to 104$)$

115 (-2.8 to 233$)$

131 (-33.9 to 296) 185 (42.7 to 327 )
0.100

0.043

0.223

0.007

0.007

0.013

0.056

0.117

0.012 
Maximum spleen length, $\mathrm{cm}$ - mean (SD)

Pain Pressure Threshold finger nail, N/cm² - mean (SD)

Pain Pressure Threshold trapezius muscle, $\mathrm{N} / \mathrm{cm}^{2}$ - mean (SD)

Blood Haemoglobin concentration, g/dL - mean (SD) ${ }^{2}$

Blood Platelet count, $10^{9}$ cells/L - mean (SD)

Serum Alanine Transaminase (ALT), IU/L - median (IQR)

Serum Gamma-Glutamyl Transpeptidase (GGT), IU/L- median (IQR)

Serum Total Bilirubin, $\mu$ mol/L- median (IQR)

Plasma International Normalized Ratio (INR) - median (IQR)

Serum Creatinine, $\mu \mathrm{mol} / \mathrm{L}$ - mean (SD)

Serum Creatinine Kinase (CK), IU/L - median (IQR)

Serum 25-OH-Vitamin D, nmol/L - mean (SD)

Serum Vitamin $\mathrm{B}_{12}$, pmol/L - median (IQR)

\section{Emotions}

Hospital Anxiety and Depression Scale (HADS), total score - mean (SD)

HADS Subscore: Anxiety - mean (SD)

HADS Subscore: Depression - mean (SD)

Toronto Alexithymia Scale-20 (TAS-20), total score - mean (SD) ${ }^{1}$

TAS-20 Subscore: Difficulty identifying feelings - mean (SD)

TAS-20 Subscore: Difficulty describing feelings - mean (SD)

TAS-20 Subscore: Externally oriented thinking - mean (SD) ${ }^{1}$

Penn State Worry Questionnaire, total score - mean (SD)

Brief Illness Perception Questionnaire, total score - mean (SD)

\section{Infection}

Epstein-Barr Virus (EBV) load, copies in blood - no. (\%)

Negative $(<160)$

Low (1600 to 2000)

Moderate/high (>2000)

$\mathrm{BV}$ virus load, copies in throat - no. (\%)

$\begin{array}{ccc}12.6(1.7) & 129(-179 \text { to } 437) & 0.411 \\ 10.5(4.5) & 14.1(-96.9 \text { to } 125) & 0.802 \\ 5.4(3.1) & 27.6(-136 \text { to } 191) & 0.740 \\ 12.7(1.2) & 382(-72.2 \text { to } 837) & 0.099 \\ 238(58.3) & -5.1(-14.2 \text { to } 4.1) & 0.275 \\ 33.0(23) & -0.7(-13.2 \text { to } 11.9) & 0.914 \\ 27.0(26) & -11.1(-30.3 \text { to } 8.1) & 0.255 \\ 10.0(6) & -43.4(-146 \text { to } 59.5) & 0.406 \\ 1.1(0.6) & 1451(-4295 \text { to } 7197) & 0.619 \\ 63.5(10.0) & -21.8(-72.9 \text { to } 29.3) & 0.401 \\ 53.0(36) & 1.7(-3.4 \text { to } 6.7) & 0.510 \\ 57.5(20.9) & 6.7(-19.2 \text { to } 32.6) & 0.609 \\ 320(170) & 2.1(-2.0 \text { to } 6.1) & 0.320\end{array}$

$11.2(5.8) \quad-113(-203$ to 24.0$) \quad 0.013$

$6.4(3.2) \quad-163(-328$ to 1.4$) \quad 0.052$

$4.8(3.6) \quad-183(-334$ to -32.1$) \quad 0.018$

$51.9(10.8) \quad-32.4(-82.9$ to 18.0$) \quad 0.206$

$19.5(6.9) \quad-71.7(151$ to 7.5$) \quad 0.076$

$21.4(6.9) \quad-37.1(-152$ to 78.3$) \quad 0.527$

$11.0(2.7)$

54.4 (-142 to 251$)$

0.585

$43.1(12.5)$

$-39.9(-81.5$ to 1.7$)$

0.060

$40.9(10.8)$

-14.6 (-64.0 to 34.8$)$

0.560

$-97.2(-182$ to 12.3$)$

0.025

-147 (-321 to 26.7)

-139 (-282 to 2.7$)$

0.055

$-35.3(-94.8$ to 24.2$) \quad 0.234$

-75.7 (-176 to 24.7$) \quad 0.132$

$-39.7(-170$ to 90.3$) \quad 0.539$

42.3 (-197 to 281) $\quad 0.719$

-38.3 (-79.8 to 3.2$)$
0.518

49 (24.9)

115 (58.4)

$33(16.8)$

$-512(.1785$ to 762$)$

0.429

-972 (-2672 to 728$)$

0.261

0.695 
Negative

Low (threshold cycle in PCR (CT), values >32)

Moderate (CT values 28 to 32 )

High (CT values $<28)$

EBV Viral Capsid Antigen (VCA) IgM, titer - median (IQR) EBV-VCA-IgG, titer - median (IQR)

EBV Nuclear Antigen (EBNA) IgG, titer - median (IQR)

Cytomegalovirus (CMV) IgM, titer - median (IQR)

CMV IgG, titer - median (IQR)

Borrelia burgdorferi IgM, titer - no. (\%)

$$
\begin{aligned}
& \text { Negative } \\
& \text { Reactive } \\
& \text { Greyzone } \\
& \text { Positive }
\end{aligned}
$$

B. burgdorferi IgG, titer - no. (\%)

Negative

Greyzone

Positive
$10(5.2)$

$26(13.5)$

$128(66.7)$

28 (14.6)

$160(73)$

$69.00(67)$

$0.00(0)$

$0.0(0.0)$

$0.0(323)$

77.1 (-2063 to 2217$)$

0.943

635.8 (-1088 to 2359$)$

0.467

0.886

$-2.7(-13.5$ to 8.1$) \quad 0.623$

-0.8 (-6.6 to 4.9$) \quad 0.775$

$-3.0(-2331$ to 2325$) \quad 0.998$

$400(-228$ to 1028$) \quad 0.210$

$0.7(-1.9$ to 3.4$) \quad 0.608$

0.317

$99(50)$

$61(30.8)$

$17(8.6)$

$21(10.6)$

0.836

0.118

0.474

0.670

$191(96.5)$

0.379

420 (-4418 to 5258$)$

0.864

\section{Immunity}

Serum high sensitive CRP, mg/L - median (IQR)

$0.40(0.86)$

$12.0(2.7)$

$1.5(0.7)$

Serum total IgM, g/L - mean (SD)

Serum total $\operatorname{Ig} \mathrm{A}, \mathrm{g} / \mathrm{L}$ - mean (SD)

Blood Leukocyte total count, $10^{9}$ cells/L - median (IQR)

Blood Lymphocyte count, $10^{9}$ cells/L - median (IQR)

Blood Monocyte count, $10^{9}$ cells/L - median (IQR)

Blood Neutrophil count, $10^{9}$ cells/L - median (IQR)

Blood Eosinophil count, $10^{9}$ cells/L - median (IQR)

Blood Basophil count, $10^{9}$ cells $/ \mathrm{L}$ - median (IQR)

Blood T cell $\left(\mathrm{CD}^{+}\right)$total count, $10^{6}$ cells/L - median (IQR)

$\begin{array}{cc}56.7 \text { (-153 to } 266) & 0.569 \\ -217 \text { (-405 to }-27.8) & 0.025 \\ -565 \text { (-1296 to } 166) & 0.129 \\ -267(-828 \text { to } 294) & 0.349 \\ 29.9(-365 \text { to } 425) & 0.881 \\ -100 \text { (-816 to } 616) & 0.783 \\ -901(-3627 \text { to } 1825) & 0.515 \\ 108 \text { (-432 to } 649) & 0.693 \\ 1588 \text { (-1780 to } 4955) & 0.353 \\ -2979(-14069 \text { to } 8112) & 0.597 \\ -0.4(-1.3 \text { to } 0.4) & 0.330\end{array}$

$2.2(0.9)$

$5.2(1.7)$

$2.3(0.8)$

$0.5(0.3)$

$2.2(1.2)$

$0.1(0.1)$

$0.0(0.1)$

$1793(710)$
-189 (-402 to 24.5$)$ 
Blood T cell ( $\left.\mathrm{CD}^{+}\right)$fraction (of lymfocyte count), \% - mean (SD)

$\begin{array}{ccc}81.3(8.3) & -59.6(-141 \text { to } 21.8) & 0.150 \\ 0.7(0.5) & -71.7(-1666 \text { to } 1522) & 0.929 \\ 842(463) & -0.7(-1.9 \text { to } 0.5) & 0.267 \\ 40.5(9.7) & -27.3(-83.5 \text { to } 28.9) & 0.339 \\ 28.5(10.5) & 0.4(-49.1 \text { to } 49.9) & 0.988 \\ 5.2(5.8) & 1.0(-101 \text { to } 103) & 0.985 \\ 753(274) & -0.8(-2.9 \text { to } 1.3) & 0.436 \\ 34.3(7.9) & -1.3(-68.1 \text { to } 65.5) & 0.970 \\ 69.0(10.3) & 27.9(-21.6 \text { to } 77.4) & 0.267 \\ 61.4(12.2) & 7.9(-34.5 \text { to } 50.3) & 0.712 \\ 6.4(2.9) & -62.0(-202 \text { to } 77.4) & 0.381 \\ 5.3(2.0) & 184(-150 \text { to } 518) & 0.279 \\ 51.0(11.4) & -14.3(-61.2 \text { to } 32.6) & 0.548 \\ 168(109) & 2.1(-3.4 \text { to } 7.6) & 0.454 \\ 7.4(4.9) & 59.8(-12.8 \text { to } 132) & 0.106 \\ 81.4(8.1) & 15.3(-49.2 \text { to } 79.9) & 0.640 \\ 4.3(4.7) & 197(44.1 \text { to } 350) & 0.012 \\ 4.1(4.0) & -48.3(-193 \text { to } 96.3) & 0.510 \\ 8.1(5.4) & -13.2(-135 \text { to } 108) & 0.830 \\ 0.3(0.5) & -245(-668 \text { to } 179) & 0.256 \\ 1.8(1.8) & 61.2(-250 \text { to } 372) & 0.698 \\ 192(149) & 1.5(-1.8 \text { to } 4.8) & 0.372 \\ 26.6(7.3) & 36.5(-37.4 \text { to } 110.4) & 0.330 \\ & & \\ & & \end{array}$

Blood cytotoxic $\mathrm{T}$ cell $\left(\mathrm{CD}^{+}\right)$count, $10^{6}$ cells/L- median (IQR)

Blood cytotoxic T cell $\left(\mathrm{CD}^{+}\right)$fraction (of lymfocyte count), \% - mean (SD)

Blood early effector memory $\mathrm{T}$ cell subset (of $\mathrm{CD} 8^{+}$count), \% - mean (SD)

Blood late effector memory $\mathrm{T}$ cell subset (of $\mathrm{CD} 8^{+}$count), \% - median (IQR)

Blood helper T cell $\left(\mathrm{CD}^{+}\right)$count, $10^{6}$ cells/L - median (IQR)

Blood helper T cell $\left(\mathrm{CD}^{+}\right)$fraction (of lymfocyte count), \% - mean (SD)

Blood recent thymic emigrant $\mathrm{T}$ cell subset (of $\mathrm{CD} 4{ }^{+} \mathrm{CD} 45 \mathrm{RA}+\mathrm{T}$ cell count), \% mean (SD)

Blood naïve $\mathrm{T}$ cell subset (of $\mathrm{CD} 4^{+}$count), $\%$ - mean (SD)

Blood follicular T cell subset (of $\mathrm{CD} 4^{+}$count), \% - median (IQR)

Blood regulatory $\mathrm{T}$ cell subset (of $\mathrm{CD} 4^{+}$count), \%- median (IQR)

Blood memory $\mathrm{T}$ cell subset (of $\mathrm{CD} 4^{+}$count), $\%$ - mean (SD)

Blood B cell $\left(\mathrm{CD} 19^{+}\right)$total count, $10^{6}$ cells/L - median (IQR)

Blood B cell (CD19+) fraction (of lymfocyte count), \% - median (IQR)

Blood naïve B cell subset (of CD19+ count), \% - mean (SD)

Blood transitoric B cell subset (of CD19+ count), \% - median (IQR)

Blood class switch B cell subset (of CD19+ count), \% - median (IQR)

Blood IgM memory B cell subset (of CD19+ count), \% - median (IQR)

Blood plasmablast subset (of CD19+ count), \% - median (IQR)

Blood CD21 ${ }^{\text {low }} \mathrm{B}$ cell subset (of CD19+ count), \% - median (IQR)

Blood NK cells $\left(\mathrm{CD} 16^{+} \mathrm{CD} 56^{+} \mathrm{CD}^{-}\right)$count, $10^{6}$ cells/L - median (IQR)

NK cell function fraction (degranulated NK cells of total NK cell count), \% - mean (SD)

1533 (693)

$-0.1(-1.1+0.9)$

0.848

Plasma Norepinephrine, pmol/L - mean (SD)

$0.0104(0.01)$

$-12757(-112236$ to 86722$)$

0.800

Urine Norepinephrine:Creatinine ratio, nmol/mmol - median (IQR)

Plasma Epinephrine, pmol/L - median (IQR)

Urine Epinephrine:Creatinine ratio, nmol/mmol - median (IQR)

Plasma Adrenocorticotropic Hormone (ACTH), pmol/L - median (IQR)

$-0.8(-2.8$ to 1.2$)$

$-30251.5(-434978.0$ to $374475.0)$

$-51.4(-224$ to 122$)$
162 ( 16.1 to 307$)$
$0.0017(0.0)$

$4.3(3.2)$
0.441

0.883

0.558 
Urine Cortisol:Creatinine ratio, $\mathrm{nmol} / \mathrm{mmol}$ - median (IQR)

Serum Thyroid Stimulating Hormone (TSH), mIE/L - median (IQR)

$\begin{array}{ccc}2.1(1.3) & -195(-666 \text { to } 276) & 0.415 \\ 11.0(2) & 132(-434 \text { to } 171) & 0.391 \\ 0.9(4.8) & -133(-257 \text { to }-9.5) & 0.035 \\ 49.3(21.5) & 30.1(0.3 \text { to } 59.8) & 0.048 \\ 200(100) & -1.7(-8.5 \text { to } 5.1) & 0.623 \\ & \text { B (CI) } & \text { sig. } \\ 9.0(1.9) & -1.7(-274 \text { to } 270) & 0.990 \\ 6.2(1.9) & 18.7(-250 \text { to } 288) & 0.891 \\ 28.1(4.0) & 53.6(-75.1 \text { to } 182) & 0.412 \\ 9.9(1.8) & 50.2(-242 \text { to } 343) & 0.735 \\ & 581(-719 \text { to } 1880) & 0.379\end{array}$

Serum free Thyroxine, pmol/L - median (IQR)

Serum Growth Hormone, $\mu \mathrm{g} / \mathrm{L}$ - median (IQR)

Serum Insulin-like Growth Factor (IGF-1), nmol/L - median (IQR)

Serum Prolactine, mIU/L - median (IQR)

\section{Cognition}

Digit Span Forward, total sum score - mean (SD)

Digit Span Backward, total sum score - mean (SD)

Hopskin s Verbal Learning Test-Revised (HVLT-R) Learning/Immediate Recall, total sum score - mean (SD)

HVLT-R Delayed Recall, total sum score - mean (SD)

HVLT-R Correct Recognition

$$
\begin{aligned}
& \text { All correct - no. (\%) } \\
& \text { Less than all correct - no. (\%) }
\end{aligned}
$$

HVLT-R False Recognition

$$
\begin{aligned}
& \text { No false recognition - no. (\%) } \\
& \text { One or more false recognition - no. (\%) }
\end{aligned}
$$

Color-Word Interference (CWI) condition 1, T-score - median (IQR)

CWI condition 2, T-score - median (IQR)

CWI condition 3, T-score - median (IQR)

CWI condition 3, no. of errors - median (IQR)

CWI condition 4, T-score - median (IQR)

CWI condition 4, no. of errors - median (IQR)

Wechsler Abbrivated Scale of Intelligence, 4th edition (WASI-IV) Materix resoning,

T-scores

$162(81)$

38 (19)

$177(-1111$ to 1465$)$

$158(79)$

$42(21)$

$31(7)$

$23(6)$

$51.5(16)$

2 (2)

57 (16)

2 (3)

$27.7(4.6)$

$59.8(7.5)$

$\begin{array}{ll}-1.9(-88.9 \text { to } 85.0) & 0.965 \\ -16.7(-134 \text { to } 100) & 0.779 \\ 7.6(-33.6 \text { to } 48.8) & 0.716 \\ -99.3(-357 \text { to } 158) & 0.447 \\ 3.3(-39.1 \text { to } 45.7) & 0.878 \\ -90.9(-362 \text { to } 181) & 0.510 \\ 7.1(-103 \text { to } 118) & 0.899 \\ 31.1(-37.0 \text { to } 99.3) & 0.368\end{array}$

Estimated Full-Scale Intelligence Quotient (IQ) - mean (SD) 
Heart Rate (HR) supine, beats/min - mean (SD)

Systolic Blood Pressure (SBP) supine, mmHg - mean (SD)

Diastolic Blood Pressure (DBP) supine, mmHg - mean (SD)

Total Periferal Resistance Index (TPRI) supine, $\mathrm{mmHg} / \mathrm{L} / \mathrm{min} / \mathrm{m}^{2}$ - mean (SD)

High Frequency Variability of the RR-interval (HF-RRI) supine, $\mathrm{ms}^{2}$ - median (IQR)

Low Frequency Variability of the RR-interval (LF-RRI) supine, $\mathrm{ms}^{2}$ - median (IQR)

LF-RRI:HF-RRI ratio supine - median (IQR)

Low Frequency Variability of Diastolic Blood Pressure (LF-DBP) supine, $\mathrm{mmHg}^{2}$ median (IQR)

HR response to Controlled Breathing (CB), beats/min - mean (SD)

$\mathrm{SBP}$ response to $\mathrm{CB}, \mathrm{mmHg}$ - mean $(\mathrm{SD})$

$\mathrm{DBP}$ response to $\mathrm{CB}, \mathrm{mmHg}$ - mean $(\mathrm{SD})$

TPRI response to $\mathrm{CB}, \mathrm{mmHg} / \mathrm{L} / \mathrm{min} / \mathrm{m}^{2}$ - mean (SD)

HF-RRI response to $\mathrm{CB}, \mathrm{ms}^{2}$ - median (IQR)

LF-RRI response to $\mathrm{CB}, \mathrm{ms}^{2}$ - mean $(\mathrm{SD})$

LF-RRI:HF-RRI ratio response to CB - mean (SD)

LF-DBP response to $\mathrm{CB}, \mathrm{mmHg}^{2}$ - mean (SD)

HR response to Orthostatic Challenge (OC), beats/min - mean (SD)

$\mathrm{SBP}$ response to $\mathrm{OC}, \mathrm{mmHg}$ - mean $(\mathrm{SD})$

DBP response to OC, $\mathrm{mmHg}$ - mean (SD)

TPRI response to OC, $\mathrm{mmHg} / \mathrm{L} / \mathrm{min} / \mathrm{m}^{2}$ - mean (SD)

HF-RRI response to OC, $\mathrm{ms}^{2}$ - median (IQR)

LF-RRI response to OC, $\mathrm{ms}^{2}$ - mean (SD)

LF-RRI:HF-RRI ratio response to OC - mean (SD)

LF-DBP response to OC, $\mathrm{mmHg}^{2}$ - mean (SD)

\section{Function}

Functional Disability Inventory, total score - mean (SD)

Pediatric Quality of Life (PedsQL), total score - mean (SD)

Steps/day, number - mean (SD)

\begin{tabular}{|c|c|c|c|c|}
\hline $65.1(9.3)$ & $-98.4(-154$ to -42.6$)$ & 0.001 & $-83.6(-141.2$ to -26.1$)$ & 0.005 \\
\hline $98.9(8.6)$ & $41.8(-16.7$ to 100$)$ & 0.160 & & \\
\hline $59.5(6.7)$ & 19.9 (-56.7 to 96.4$)$ & 0.609 & & \\
\hline $12.7(2.2)$ & 52.5 (-281 to 386$)$ & 0.756 & & \\
\hline $1054(1703)$ & $0.1(-0.1$ to 0.3$)$ & 0.311 & & \\
\hline $663(910)$ & $0.3(-0.1$ to 0.8$)$ & 0.173 & & \\
\hline $0.63(0.56)$ & $197(-840$ to 1234$)$ & 0.708 & & \\
\hline $3.0(3.0)$ & 26.0 (-105 to 157$)$ & 0.696 & & \\
\hline $0.95(2.8)$ & $-96.1(-280$ to 88.0$)$ & 0.304 & & \\
\hline $0.12(5.6)$ & -71.8 (-165 to 21.6$)$ & 0.131 & & \\
\hline$-3.38(4.76)$ & $-79.6(-188$ to 29.1$)$ & 0.150 & & \\
\hline$-0.18(0.61)$ & $-577(-1427$ to 273$)$ & 0.182 & & \\
\hline 101 (1294) & $-0.3(-0.9$ to 0.3$)$ & 0.328 & & \\
\hline$-333(431)$ & $0.1(-0.3$ to 0.5$)$ & 0.762 & & \\
\hline$-0.21(0.56)$ & $-354(-1495$ to 787$)$ & 0.541 & & \\
\hline$-0.75(1.91)$ & $-11.5(-279$ to 257$)$ & 0.933 & & \\
\hline 30.1 (11.6) & 31.7 (-13.3 to 76.6$)$ & 0.166 & & \\
\hline$-1.48(10.4)$ & $-8.2(-58.9$ to 42.5$)$ & 0.750 & & \\
\hline $7.18(8.99)$ & $10.7(-47.5$ to 69.0$)$ & 0.716 & & \\
\hline $0.83(1.58)$ & $9.8(-324$ to 344$)$ & 0.954 & & \\
\hline$-1369(2237)$ & $-0.1(-0.4$ to 0.1$)$ & 0.274 & & \\
\hline$-98.2(1652)$ & $-0.1(-0.4$ to 0.2$)$ & 0.453 & & \\
\hline $1.91(1.69)$ & 50.4 (-264 to 365$)$ & 0.752 & & \\
\hline$-0.51(2.50)$ & $-33.9(-246$ to 178$)$ & 0.753 & & \\
\hline $16.6(11.8)$ & $-69.0(-113$ to -24.7$)$ & 0.002 & $-59.1(-106$ to -12.8$)$ & 0.013 \\
\hline $66.5(17.4)$ & 50.8 (21.0 to 80.7$)$ & 0.001 & $45.1(15.1$ to 75.1$)$ & 0.003 \\
\hline $7515(3080)$ & $0.4(0.3$ to 0.6$)$ & $<0.001$ & $0.4(0.2$ to 0.6$)$ & $\begin{array}{c}<0.00 \\
1\end{array}$ \\
\hline
\end{tabular}


n.a.=not applicable. ${ }^{1}$ Subscales in which total score or other subscales in the same questionnaire were significant, were imputed despite a insignificant bivariate linear regression finding. ${ }^{2}$ Variables in which gender acted as a confounder were not included in the multiple imputation. A total of 306 statistical tests are desplayed in this table; a Bonferroni-correction for test multiplicity suggests a level of signifance at $0,05 / 188=0,0003$

\section{Table S2. Baseline predictors of physical activity six months after acute EBV infection. Multiple linear regression models addressing the effect of sex} differences.

\begin{tabular}{|c|c|c|c|c|c|c|c|c|c|}
\hline & \multicolumn{2}{|c|}{$\begin{array}{l}\text { Multiple linear model including } \\
\operatorname{sex}(n=200)\end{array}$} & \multicolumn{2}{|c|}{$\begin{array}{l}\text { Multiple linear model in female } \\
\text { subgroup }(n=129)\end{array}$} & \multicolumn{2}{|c|}{$\begin{array}{l}\text { Multiple linear model in male } \\
\text { subgroup }(n=71)\end{array}$} & \multicolumn{3}{|c|}{$\begin{array}{c}\text { Multiple linear model based on wide inclusion of } \\
\text { variables }\end{array}$} \\
\hline & $\mathrm{B}(\mathrm{CI})$ & p-value & $\mathrm{B}(\mathrm{CI})$ & p-value & $\mathrm{B}(\mathrm{CI})$ & p-value & $\mathrm{B}(\mathrm{CI})$ & p-value & $\Delta \operatorname{adj} . R^{25}$ \\
\hline Steps/day, number & $0.4(0.2$ to 0.6$)$ & $<0.001$ & $0.5(0.3$ to 0.6$)$ & $<0.001$ & $0.3(-0.0$ to 0.6$)$ & 0.055 & 0.31 (0.13 to 0.49$)$ & 0.001 & 0.062 \\
\hline Usage of alcoholic beverages ${ }^{1}$ & $-1752(-2856$ to -648$)$ & 0.002 & $-1440(-2790$ to -89.9$)$ & 0.037 & $-2336(-4220$ to -452$)$ & 0.015 & $-1472(-2632$ to -313$)$ & 0.014 & 0.035 \\
\hline Usage of narcotics/illicit drugs ${ }^{2}$ & 2075 (563 to 3586$)$ & 0.007 & $1457(-712$ to 3626$)$ & 0.185 & 2803 (365 to 5242$)$ & 0.024 & 2430 (978 to 3883$)$ & 0.001 & 0.041 \\
\hline Serum Growth Hormone, $\mu \mathrm{g} / \mathrm{L}$ & $-140(-267$ to -13.8$)$ & 0.030 & $-121(-247$ to 5.0$)$ & 0.060 & $-170(-649$ to 310$)$ & 0.486 & $-105(-222$ to 11.8$)$ & 0.078 & 0.010 \\
\hline Sex & $1144(-1283$ to 996$)$ & 0.804 & & & & & & & \\
\hline Sleepy at daytime ${ }^{3}$ & & & & & & & $107(-52.9$ to 267$)$ & 0.179 & 0.011 \\
\hline $\begin{array}{l}\text { Heart Rate (HR) supine, beats/min } \\
\text { Toronto Alexithymia Scale- } 20 \text { (TAS- }\end{array}$ & & & & & & & $-49.6(-106$ to 6.72$)$ & 0.084 & 0.011 \\
\hline $\begin{array}{l}\text { 20), total score } \\
\text { TAS-20 Subscore: Externally oriented }\end{array}$ & & & & & & & $-25.8(-125$ to 73.0$)$ & 0.570 & 0.005 \\
\hline thinking & & & & & & & $155(-138$ to 448$)$ & 0.279 & 0.009 \\
\hline Serum total IgG, g/ - mean (SD) & & & & & & & $-131(-320$ to 57.3$)$ & 0.169 & 0.007 \\
\hline $\begin{array}{l}\text { Explained varience (adjusted } \mathrm{R}^{2} \text { ) of } \\
\text { model }^{4}\end{array}$ & 0.201 & & 0.231 & & 0.119 & & & & \\
\hline
\end{tabular}


